\title{
Natural-fibre-reinforced plastics in actively bent structures
}

Christoph Gengnagel Dr Ing

Professor, Department of Structural Design and Technology, University of the Arts Berlin, Germany
Elisa Lafuente Hernández Dipl, Ing

Research Assistant, Department of Structural Design and Technology, University of the Arts Berlin, Germany

Ralf Bäumer Dipl, Ing

Senior Scientist, Faserinsttut Bremen e.V., Bremen, Germany

This joint venture research brings together three different fields of research which have led to novel findings: these relate to single-motion erection of irregular lattice gridshells using geometric optimisation techniques for the application of natural fibre-reinforced composites within the context of actively bent elements for curved load-bearing structures. Fabrication tests are carried out for pultruded flat test specimens and tubular sections made from environmentally advantageous composites with flax or sisal fibres and a partially bio-based resin. The flat test specimens with flax fibres exhibit excellent tensile and bending strength properties but the sisal yarns prove more successful for pultrusion. Fibre-reinforced composites (including natural fibre-reinforced plastics) compare favourably to timber and steel for application in actively bent structures where low weight, bending-stress reserves and large curvatures are required. The pultrusion tests also identify serious manufacturing challenges (such as the twisting of sisal fibres), which lead to inconsistent properties and subsequently highlight the need for further investigation. The experimental realisation of a $10 \mathrm{~m}$ span irregular lattice gridshell using glass fibre-reinforced plastic was completed as a proof of concept for the suitability of active bending for pultruded fibre-reinforced profiles and also to validate newly developed computational optimisation and construction procedures for irregular gridshell lattices.

\section{Introduction}

The term 'active bending' describes the elastic deformation of linear or planar elements in order to achieve curved structural geometries. The main motivation for its use lies in the simplicity of producing curved geometries from straight elements. While various empirical construction methods in vernacular architecture made use of the elastic behaviour of their building materials (e.g. nomadic tents of the Middle East), only few examples are to be found in twentieth century architecture. The Multihalle in Mannheim (Burkhardt et al., 1978), based on hanging models and simple analytical approaches, is representative of how elastic deformation can be employed as an economical construction method for doubly curved shell structures.

Recent developments in computational simulation (such as powerful dynamic relaxation and finite-element analysis (FEA) tools) now offer the possibility of forming and analysing structures that derive their complex, curved geometry solely from an erection process in which they are elastically deformed. This is the basis for various explorations that include new types of surface and gridshells (Bouhaya et al., 2011; Douthe et al., 2006), membranes with elastically bent battens, bent structural components with membranes as restraining systems (Alpermann and Gengnagel, 2009), and various types of adaptive and elastic kinetic structures (Lienhard et al., 2012). The examples presented in Figure 1 may differ in their construction owing to different cultural and historical backgrounds, but they all have curved geometries based on straight or planar building elements created by means of elastic bending.

The advantageous combination of a low modulus of elasticity and a high bending tensile strength makes composite materials ideal for active bending structures. In the built environment, the application of fibre-reinforced composites is almost exclusively restricted to glass-fibre-reinforced plastics (GFRPs) or carbonfibre-reinforced plastics (CFRPs). While these materials feature extraordinary load-bearing capacity, they are also characterised by significant ecological disadvantages, such as high energy consumption and environmental impact during production as well as limited recyclability. Composites made from rapidly renewable raw materials, such as natural-fibre-reinforced plastics (NFRPs), offer a viable alternative with high potential for development (Gengnagel and Lafuente Hernández, 2011).

\section{Active bending}

\subsection{Actively bent and curved structures}

Actively bent elements are transformed by elastic bending from a stress-free initial geometry to a desired final geometry with resultant residual stresses. On the whole, planar elements are 


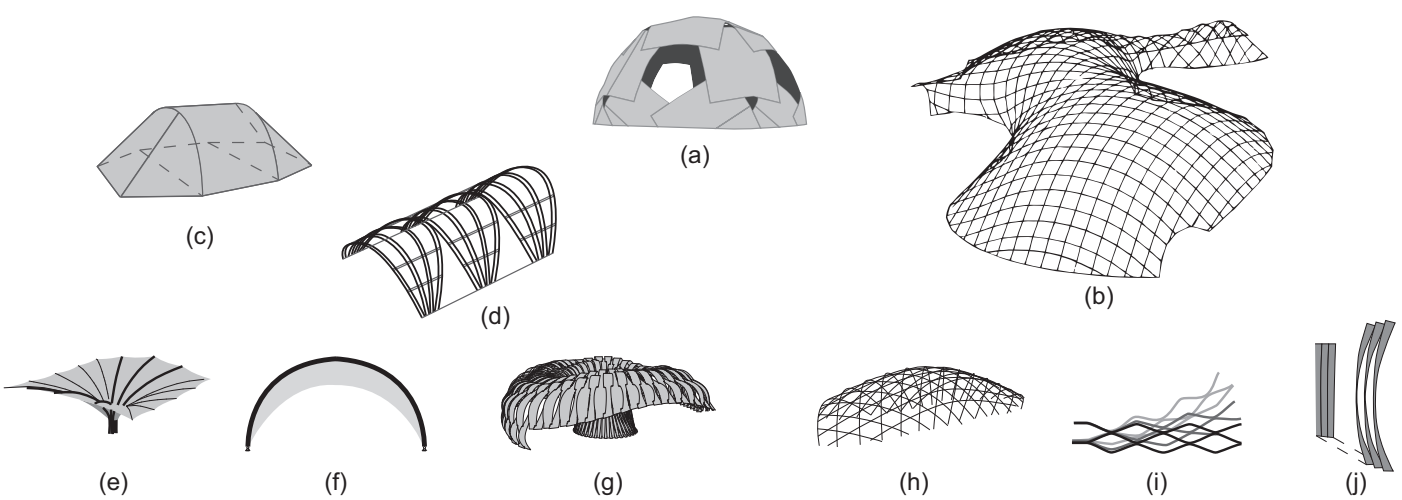

Figure 1. Examples of actively bent structures: (a) plywood dome in 1957; (b) expedition tents in the 1970s; (c) Multihalle Mannheim in 1974; (d) Hooke Park Workshop in 1990; (e) Marrakech
Umbrella in 2011; (f) membranes restrained elements 1999-2012; (g) Research Pavilion ICD/ITKE in 2002; (h) Gridshell in 2011; (i) Hybgrid in 2002; (j) Flectofin ${ }^{\circledR}$ project in 2012 significantly more economical to manufacture than curved elements. Herein lies the simple key advantage of actively bent structures. Curved elements on the other hand can be made to be stress-free in their final curved geometric state.

The advantage of elastically bent elements is that the production process is potentially identical for all elements, regardless of their curvature. The transportation of straight profiles is easier owing to volume reductions. The use of straight elements can also facilitate the assembly and erection processes, as the flat elements can be laid out on the ground, pre-assembled and erected afterwards. This can reduce or circumvent the use of scaffolding.

\subsection{Structural behaviour of actively bent elements}

The disadvantage of elastically bent elements is the residual stress caused by the bending process. The higher is the residual stress after bending, the lower is the stress reserve under external loads. Therefore, the residual stress should be as low as possible. On the assumption of linear elastic material behaviour, the residual stress caused by bending along one axis is defined as

$$
\sigma(z)=E z \frac{1}{R}
$$

where $E$ is the Young's modulus of the material, $z$ is the height in the section relative to the neutral axis and $R$ is the radius of the curvature (Figure 2). In order to reduce the residual stress, the $E$ modulus and the cross-sectional height can be reduced or the radius can be increased. The cross section of elastically bent elements is often chosen with a low height and a large width in order to reduce the residual stress.

In contrast, a deep cross section is necessary to resist the stresses and deformations from external loads, creating an

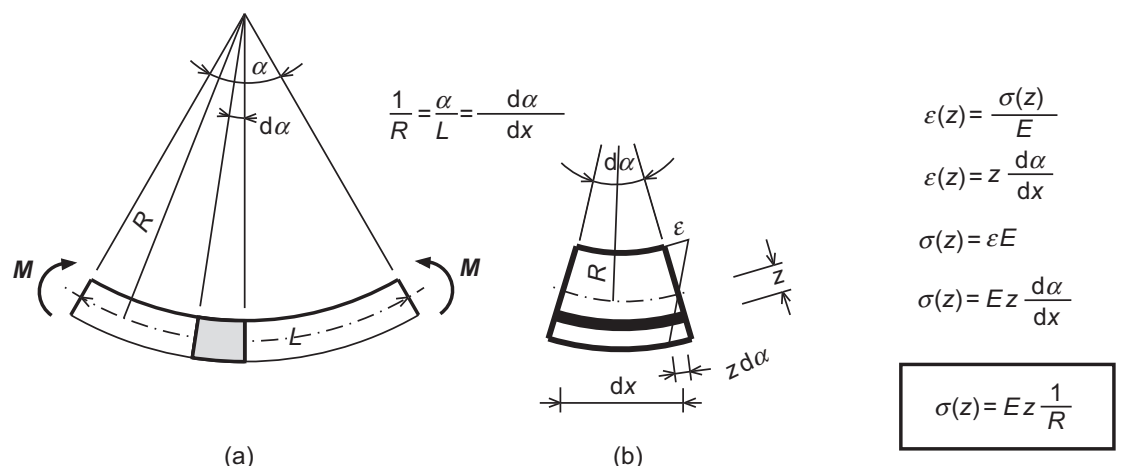

Figure 2. Relationship between the stress, radius of curvature and section depth in a deflected beam: (a) deflected beam; (b) deformed element 
Construction Materials

Volume 166 Issue CM6
Natural-fibre-reinforced plastics

in actively bent structures

Gengnagel, Lafuente Hernández

and Bäumer inherent conflict in active bending. High stiffness and high allowable curvature contradict one another.

To use elastically bent elements in structures with wide spans, actively bent elements can be combined with stiffening elements forming a 'hybrid' structure, which can lead to greatly improved stiffness thus enabling larger spans and more ambitious structures. The additional stiffening elements restrain the elastically bent elements in the desired geometry and can be added before or after the bending process.

The elastic stiffness of a structural element is dependent on the cross section, the material properties and the static system, but is independent of deformations and remains constant if boundary conditions are maintained. Geometric stiffness, however, depends on the static system, the applied loads and the deformations. The value of the geometric stiffness increases as deformations increase. An element's geometric stiffness is positive if the element is under axial tension forces and negative if it is under axial compression forces. The total stiffness is the sum of elastic and geometric stiffness. The elastic bending of elements also induces shear and axial forces. The elastic stiffness thus remains constant whereas the geometric stiffness changes; the latter may be so small that it does not affect structural behaviour or it might increase or decrease total stiffness (Alpermann et al., 2012).

\subsection{Materials}

Materials appropriate for active bending must have a low ratio of elastic modulus to bending strength in order to allow small bending radii. The most suitable materials to meet these requirements are fibre-reinforced composites such as natural and engineered timber, NFRP, bamboo, GFRP and CFRP. Figure 3 shows the elastic modulus and the allowable radii as a function of the section height for a comparison of materials.

CFRP offers a small radius and a high modulus of elasticity, making it suitable for active bending, but its high cost deters use in construction engineering. GFRP offers the next-smallest radius, followed by bamboo and NFRP, both having a much lower stiffness than CFRP and GFRP. The modulus of elasticity of natural and engineered timber is comparable to NFRP and bamboo, but the allowable radii are higher. Aluminium has approximately the same allowable curvature as timber but higher stiffness. For purposes of comparison, the values for the NFRP test specimens for this project are also displayed in the graph.

All five fibre-reinforced composites offer a wide range of properties depending on the stiffness of the matrix and fibres, bonding strength between matrix and fibres and fibre content of the composite (Table 1). The fibre-reinforced materials are characterised by anisotropic behaviour.

\section{NFRP for construction elements}

\subsection{State of the art}

The main industrial applications for NFRPs are in the automotive industry, particularly for interior trim. Despite the high load-bearing capacity of natural fibres, NFRPs with biobased matrices are practically non-existent in the construction market (van de Velde and Kiekens, 2002). The few studies investigating their structural applications make use of composites manufactured with non-cost-effective production methods or containing fossil-oil-based polymers as matrix (Burgueño et al., 2004). Dweib et al. (2004) manufactured transfer-moulded beams made of different natural fibres and soy oil-based resin.

Unidirectionally reinforced profiles with improved mechanical properties and a rapid manufacturing process (pultrusion) appear to be appropriate for structural application. Because of the high melt viscosity of thermoplastics, thermoset resins are better suited for pultrusion. Partially bio-based resins have been developed from pultrusion processes, but resins exclusively made of renewable material or with full biodegradability are still subject to research (Bäumer et al., 2013).

\subsection{Pultruded profiles}

Pultrusion is a manufacturing process for fibre-reinforced structural profiles with constant cross section and continuous length. The fibres are pulled continuously and mixed with the matrix through impregnation in a resin bath or by contact pressure in a form-giving tool.

Gensewich and Riedel (1999) created the first profiles from flax fibres and bio-based resin in 1999, achieving $88 \%$ of the stiffness of comparable GFRP profiles. Owing to moisture absorption, the values were later reduced to $51 \%$. In experiments with thermoplastic matrices, in 2002, van de Velde and Kiekens (2002) showed that profiles made from flax/ polypropylene hybrid yarns (38/62 vol.\%) could reach a bending strength of $101 \mathrm{MPa}$. After analysis and optimisation of the pultrusion parameters, heating temperature and drawing speed, Angelov et al. (2007) were able to increase this value to $125 \mathrm{MPa}$. The epoxy resin system developed by Zhu et al. (2004) as an alternative to petrochemical matrices had up to $30 \%$ soy content. Pultruded profiles with a variety of cross sections and profile lengths are interesting as structural beam components. The freedom to create profiles of any desired length allows the design of beam structures with continuous elements, avoiding weaknesses otherwise caused by nodal connections. Hollow sections offer further advantages in terms of optimisation of cross-sectional properties.

\subsection{Development of pultruded tubes}

The fundamental difference between pultrusion with GFRP and NFRP is that the natural fibre is available only as staple 


\begin{tabular}{|c|c|c|c|c|c|c|}
\hline & & $\begin{array}{l}\text { Bending } \\
\text { strength, } \\
\text { longitudinal: } \\
\mathrm{N} / \mathrm{mm}^{2}\end{array}$ & $\begin{array}{l}\text { Modulus of } \\
\text { elasticity: } \\
\mathrm{N} / \mathrm{mm}^{2}\end{array}$ & $\begin{array}{l}\text { Allow. } \\
\text { radius of } \\
\text { curvature: } \mathrm{m}\end{array}$ & $\begin{array}{l}\text { Density: } \\
\mathrm{kg} / \mathrm{m}^{3}\end{array}$ & $\begin{array}{l}\text { Strength-to- } \\
\text { weight } \\
\text { ratio: } \mathrm{Nm} / \mathrm{g}\end{array}$ \\
\hline Timber & $\begin{array}{l}\text { Structural and glued } \\
\text { laminated timber }\end{array}$ & $24-60$ & $11 \cdot 600-17 \cdot 000$ & $283-483 z$ & 380-700 & $63-86$ \\
\hline \multirow[t]{2}{*}{ Bamboo } & $\begin{array}{l}\text { Phyllostachys } \\
\text { pubescens } \\
(1-5 \text { years old })^{b}\end{array}$ & 119-185 & $8 \cdot 680-13 \cdot 410$ & $67-73 z$ & $330-660$ & $249-362$ \\
\hline & Laminated bambooc & $113-125$ & $10 \cdot 899-12 \cdot 145$ & $87-107 z$ & 600 & 189-208 \\
\hline \multirow[t]{2}{*}{ NFRP } & $\begin{array}{l}\text { Natural fibres: flax, } \\
\text { hemp, woold,e } \\
\text { Matrix: Polypropylene } \\
\text { (PP), Polyester (PEs), } \\
\text { Polyurethane (PU) } \\
\text { vinylester }^{d, e}\end{array}$ & $101-180$ & $11 \cdot 500-13 \cdot 000$ & $64-90 z$ & $800-1 \cdot 221$ & $126-147$ \\
\hline & $\begin{array}{l}\text { Sisal/Bio-based } \\
\text { polyester } \\
\text { (UdK Berlin, } \\
\text { Faserinstitut } \\
\text { Bremen) }\end{array}$ & 105-132 & $9 \cdot 040-11 \cdot 764$ & $86-89 z$ & $1 \cdot 240-1 \cdot 260$ & 85-105 \\
\hline GFRP & $\begin{array}{l}\text { Glass } \\
\text { fibres/vinylester, }{ }^{f, g, h}\end{array}$ & $224-690$ & $12 \cdot 500-41 \cdot 000$ & $46-63 z$ & $1 \cdot 800-2 \cdot 100$ & $124-329$ \\
\hline
\end{tabular}

\begin{tabular}{|c|c|c|c|c|c|c|}
\hline & & $\begin{array}{c}\text { Tensile } \\
\text { strength, } \\
\text { longitudinal: } \\
\mathrm{N} / \mathrm{mm}^{2}\end{array}$ & $\begin{array}{l}\text { Modulus of elasticity: } \\
\qquad \mathrm{N} / \mathrm{mm}^{2}\end{array}$ & $\begin{array}{c}\text { Allow. } \\
\text { radius of } \\
\text { curvature: } \mathrm{m}\end{array}$ & $\begin{array}{l}\text { Density: } \\
\mathrm{kg} / \mathrm{m}^{3}\end{array}$ & $\begin{array}{l}\text { Strength-to- } \\
\text { weight } \\
\text { ratio: } \mathrm{N} \mathrm{m/g}\end{array}$ \\
\hline $\begin{array}{l}\text { Carbon } \\
\text { fibre- } \\
\text { reinforced } \\
\text { plastic }\end{array}$ & $\begin{array}{l}\text { Carbon fibres/Vinyl } \\
\text { or epoxy, }\end{array}$ & $2 \cdot 070-2 \cdot 800$ & $131 \cdot 000-165 \cdot 000$ & $59-64 z$ & 1600 & $1 \cdot 294-1 \cdot 750$ \\
\hline
\end{tabular}

\begin{tabular}{|c|c|c|c|c|c|c|}
\hline & & $\begin{array}{c}\text { Yield } \\
\text { strength: } \\
\mathrm{N} / \mathrm{mm}^{2}\end{array}$ & $\begin{array}{l}\text { Modulus } \\
\text { of elasticity: } \mathrm{N} / \mathrm{mm}^{2}\end{array}$ & $\begin{array}{c}\text { Allow. } \\
\text { radius of } \\
\text { curvature: m }\end{array}$ & $\begin{array}{l}\text { Density: } \\
\mathrm{kg} / \mathrm{m}^{3}\end{array}$ & $\begin{array}{l}\text { Strength- } \\
\text { to-weight } \\
\text { ratio: } \\
\mathrm{N} \mathrm{m} / \mathrm{g}\end{array}$ \\
\hline Aluminium & EN AW-5754/7020k & $100-280$ & 70000 & $250-700 z$ & 27000 & $4-10$ \\
\hline
\end{tabular}

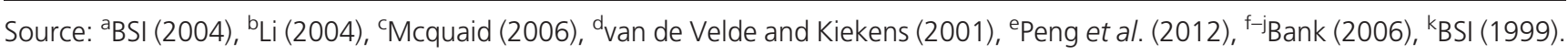

Table 1. Comparison of material properties

fibre (ca 10-50 mm). For pultrusion with NFRPs, an additional process of spinning the fibre into yarn is required. In the tests carried out for this investigation, several NFRP flat test specimens were manufactured by means of pultrusion and their properties compared. The flat test specimens are shown alongside the later tubular elements in Figure 8. Flax and sisal fibres in a yarn structure were used. The $\mathrm{S}$ and $\mathrm{Z}$ twist sisal yarn had a fineness of $\mathrm{Nm} 0 \cdot 45$ and $\mathrm{Nm} 0 \cdot 8$. The flax fibre, a raw yarn, had a fineness of $\mathrm{Nm} \mathrm{0.95}$. Raw yarn consists of fibre bands with a slight twist and serves as a semi-finished product in the textile industry. Ashland's organically based ( $22 \%$ biocontent: soybean oil and bioethanol) pultrusion resin 


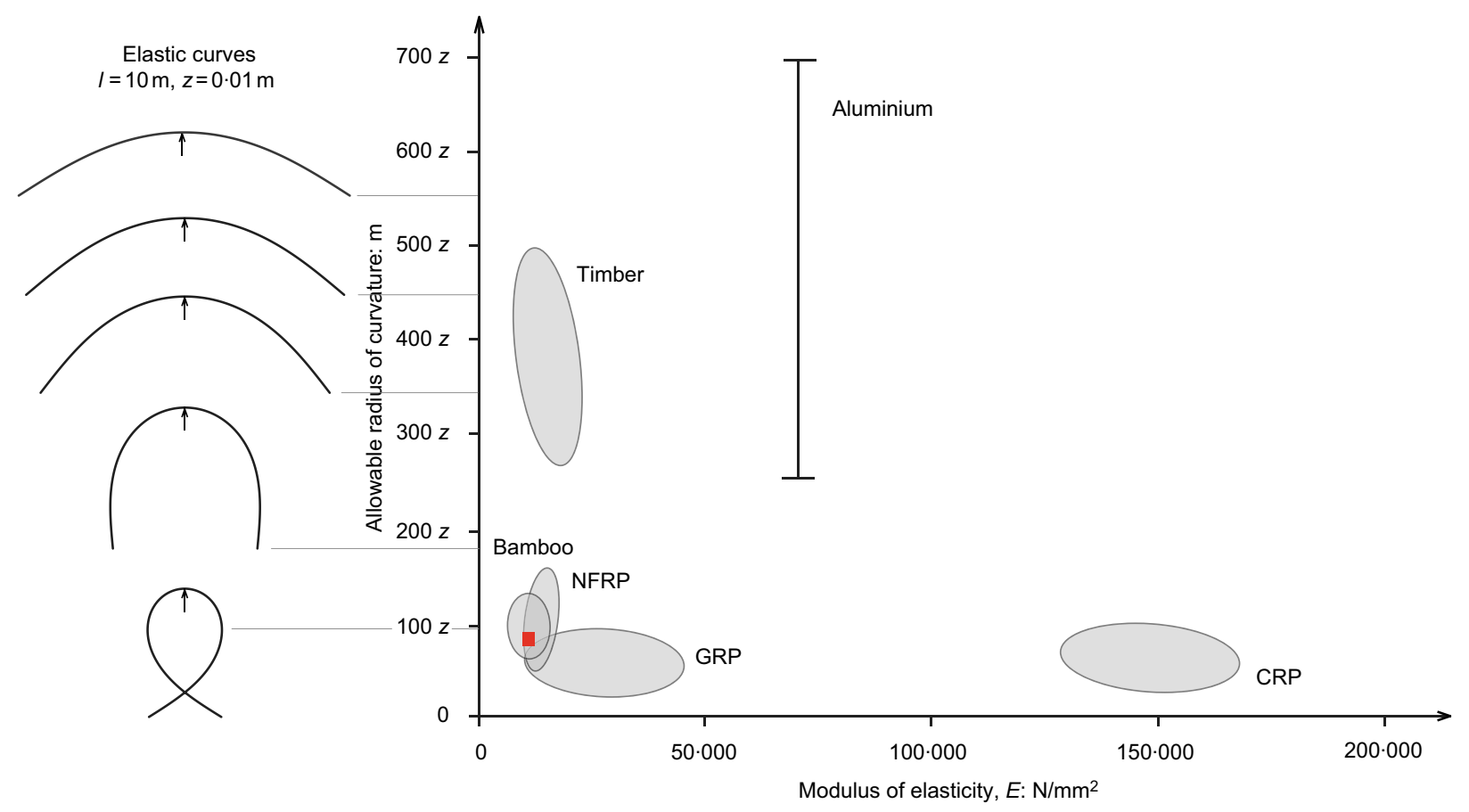

Figure 3. Material properties with respect to active bending

Envirez 70302 served as a matrix. Akzo Nobel's Trigonox C, with a mass ratio from $1 \%$ to $1 \cdot 5 \%$, was used as a hardener. Akzo Nobel's $0 \cdot 5 \%$ Perkadox 16 served as a cross-linking agent.

To investigate the mechanical characteristics of the fibre's material composition, flat test specimens measuring $10 \mathrm{~mm} \times$ $2 \mathrm{~mm}$ in section were pultruded. The yarn was drawn from a creel, continuously dried at $130^{\circ} \mathrm{C}$, led to an open resin bath, and then hardened in a mould. These profiles were reduced to the length designated in testing standards and cooled to $23^{\circ} \mathrm{C}$ and 50\% relative humidity (EN ISO 291 (ISO, 2008)), under laboratory conditions. Impact strength, flexural strain and tensile tests of the pultruded flat specimens were carried out.

A Charpy test for impact strength was performed according to the ISO 179-1 (ISO, 2010). Table 2 shows the results. The impact strength increased depending on the fineness of the fibre material, ranging between $44 \mathrm{MPa}$ and $70 \mathrm{MPa}$, thus exhibiting a low variance corresponding to automobile suppliers' specifications for reinforced fibre materials. Similar behaviour was seen in the flexural strain test, based on ISO 14125 (DIN, 2007). Here the parameters ranged between $105 \mathrm{MPa}$ and $153 \mathrm{MPa}$, with standard deviations between $9 \mathrm{MPa}$ and $12 \mathrm{MPa}$ (Table 3).

Determination of tensile characteristics was accomplished following ISO 527-5 (ISO, 2009). Digressing from the norm, no load transfer elements, like cap strips or humeral (shoulder) heads, were used. Clamping fractures appeared consequently in all specimens. The strength values ranged between $144 \mathrm{MPa}$ and $257 \mathrm{MPa}$, corresponding to parameters cited in the literature. The variances ranged from $4 \mathrm{MPa}$ to $30 \mathrm{MPa}$ (Table 4). The parameters for the $E$ modulus ranged between $9 \mathrm{GPa}$ and $15 \mathrm{GPa}$ (Table 5).

In all the tests, the higher strengths corresponded with finer yarns. This is due to the distribution of the fibre volume content. Cross sections of sisal and flax fibre specimens are presented in Figure 4. At Nm 0.45, the yarn extends across the thickness of the entire sample. At the interfaces, large resinous surfaces are evident. A more favourable distribution is achieved with finer yarn of $\mathrm{Nm} 0.80$ and 0.95 . Raw yarn not spun compactly can distribute itself flexibly in the mould cavity. Resinous spots are reduced and the fibre volume content increases.

The established density of the test specimens are noted in Table 5 . The difference between the density of sisal specimens $\mathrm{Nm} 0.45$ and $\mathrm{Nm} 0.80$ is due to their fibre volume content. The resin system used exhibited a density of $1 \cdot 15 \mathrm{~g} / \mathrm{cm}^{3}$.

For the manufacture of the tubes, a tool was used that produces a section $20 \mathrm{~mm}$ in dia. with a wall thickness of $2 \mathrm{~mm}$. For the manufacturing process, the fibre material must 


\begin{tabular}{lccc} 
Impact strength (Charpy), $n=10$ & Sisal Nm 0.45 & Sisal Nm 0.80 & Flax Nm 0.95 \\
\hline Average: MPa & $43 \cdot 6$ & $50 \cdot 5$ & $69 \cdot 7$ \\
Standard deviation: MPa & $3 \cdot 3$ & 4 & $6 \cdot 6$ \\
Variation coefficient: \% & $7 \cdot 7$ & $7 \cdot 9$ & $9 \cdot 5$
\end{tabular}

Table 2. Measured values for impact strength

Flexural strength, $n=10$

Sisal $\mathrm{Nm} 0 \cdot 45$

Sisal $\mathrm{Nm} 0 \cdot 80$

Flax Nm 0.95

\begin{tabular}{|c|c|c|c|}
\hline Average: $\mathrm{MPa}$ & $104 \cdot 9$ & $131 \cdot 6$ & $153 \cdot 3$ \\
\hline Standard deviation: MPa & $11 \cdot 9$ & $9 \cdot 2$ & $9 \cdot 0$ \\
\hline Variation coefficient: \% & $11 \cdot 3$ & $6 \cdot 9$ & $5 \cdot 9$ \\
\hline
\end{tabular}

Table 3. Measured values for flexural strength

be fed through all the phases of the process. The tensile forces entered by the pulling device must be maintained right from the dry, loose yarn at the start of the process. The flax fibre's inherent strength was insufficient, so the process was possible only with elaborate preparation; at the same time, this made it more vulnerable to failure. For this reason, the tube profiles were manufactured with sisal yarns of $\mathrm{Nm} 0.45$ and $\mathrm{Nm} 0.8$. After unwinding the fibres from the creel followed by predrying it (Figure 5), the fibres were impregnated in a resin bath (Figure 6)

The profile was hardened in the heated mould cavity and was pulled out continuously at a constant speed by alternating spoolers (Figure 6). The pulling speed varied between $20 \mathrm{~cm} / \mathrm{min}$ and $50 \mathrm{~cm} / \mathrm{min}$. The instrument's temperature could be gradually set with a four-zone heater. The maximum temperature was between 100 and $160^{\circ} \mathrm{C}$. The tubes were cut to $5 \mathrm{~m}$.

The following can be deduced from the experiment.

(a) Owing to the necessary spinning of the fibre into a yarn, the higher economic costs for the final product must be taken into account.

(b) For more reliable processing of fibre in the spinning operation, an oil finish should be applied. The oil finish, in turn, results in reduced fibre/matrix adhesion and subsequently to limited mechanical parameters.

(c) The compact twisting of the yarn impedes optimal wetting of the individual fibres.

\begin{tabular}{lccr}
\hline Tensile strength, $n=9$ & Sisal Nm 0.45 & Sisal Nm 0.80 & Flax Nm 0.95 \\
\hline Average: MPa & $144 \cdot 3$ & $178 \cdot 8$ & $256 \cdot 7$ \\
Standard deviation: MPa & $4 \cdot 5$ & $8 \cdot 4$ & $30 \cdot 1$ \\
Variation coefficient: $\%$ & $3 \cdot 1$ & $4 \cdot 7$ & $11 \cdot 7$
\end{tabular}

Table 4. Measured values for tensile strength

Modulus of elasticity, $n=9$

Sisal $\mathrm{Nm} 0 \cdot 45$

Sisal $\mathrm{Nm} 0 \cdot 80$

Flax Nm 0.95

Average: $\mathrm{MPa}$

$9039 \cdot 9$

$422 \cdot 1$

$4 \cdot 7$

Standard deviation: MPa

$1 \cdot 24$

$11764 \cdot 2$
$673 \cdot 8$
$5 \cdot 7$
$1 \cdot 26$

$14942 \cdot 8$

$786 \cdot 8$

$5 \cdot 3$

$\cdot 26$

Table 5. Measured values for modulus of elasticity and density 
Construction Materials

Volume 166 Issue CM6
Natural-fibre-reinforced plastics

in actively bent structures

Gengnagel, Lafuente Hernández

and Bäumer

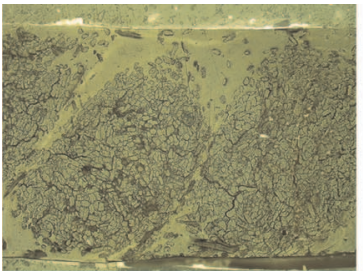

(a)

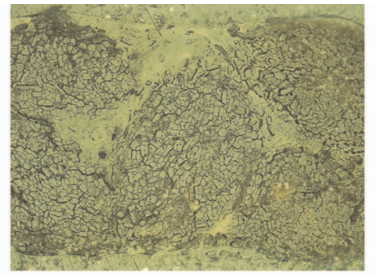

(b)

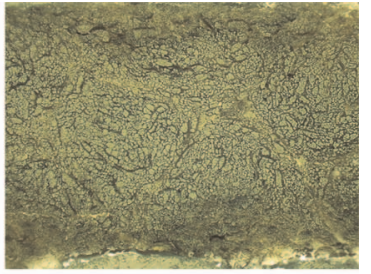

(c)

Figure 4. (a) Cross section of sisal $\mathrm{Nm} \mathrm{0.45;} \mathrm{fibre} \mathrm{volume} \mathrm{content}$ $65 \%$ ( $\times 100$ specimen thickness $2 \mathrm{~mm}$ ). (b) Cross section of sisal $\mathrm{Nm}$ 0.80; fibre volume content $70 \%$ ( $\times 100$ specimen thickness $2 \mathrm{~mm}$ ). (c) Cross section of flax Nm 0.95; fibre volume content $75 \%$ ( $\times 100$ specimen thickness $2 \mathrm{~mm}$ )

(d) The yarns form large, circular elements in the finished profiles, resulting in resinous zones, and are related to decreased fibre volume content.

(e) Because of the yarn's twist, the elemental fibres are not optimally aligned with the load path. This results in higher profile pliability when under tensile stress. The $E$ modulus decreases.

(f) The residual stresses brought about by the twisted yarn in the profile during pultrusion results in torsion of the profile. These residual stresses must be compensated for by the amount of yarn with which each $\mathrm{S}$ and $\mathrm{Z}$ twist is processed.

(g) The natural yarns are hygroscopic in general, which means they absorb moisture from the surrounding air. During processing, the humidity begins to evaporate in temperatures above $100^{\circ} \mathrm{C}$, leading to flaws in the matrix. The residual stresses in the profile can thus rise. Predrying the fibres is therefore necessary.

In spite of the limitations noted, reinforced fibre composite materials with good mechanical qualities can be manufactured by the pultrusion process.

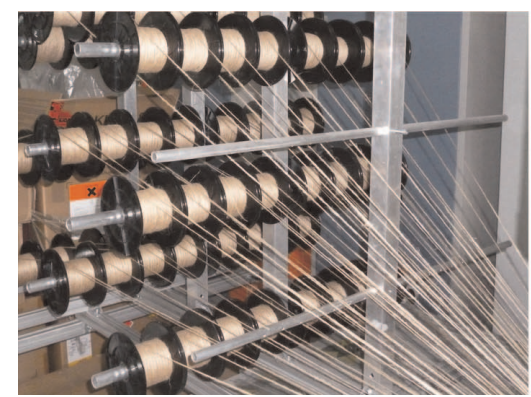

\section{Pultruded NFRP tubes for actively bent structures}

Because of the good mechanical properties of natural fibres and their potential optimal utilisation when oriented in one direction, pultruded NFRPs of relatively low rigidity can exhibit a bending strength more than six times that of structural timber (D30, according to EN 1995-1-1:2004 Eurocode 5). Compared to GFRPs, NFRPs can achieve competitive values in regard to the strength-to-weight ratios, by selecting appropriate fibre volume fractions (Table 1).

The high bending stresses to which actively bent structures are subjected during the construction phase reduce their external loadbearing capacity. This effect decreases for materials with moderate coefficients of elasticity and high mechanical strength. Complex, thin-walled profiles configured with pultrusion allow optimal use of the cross-sectional properties, reduction of the profile's weight and integration of constructive details on the sections.

Pultruded NFRP profiles (Figure 7) exhibit adequate properties as beam components for lightweight actively bent structures, such as arches and gridshells. As an environmentally friendly

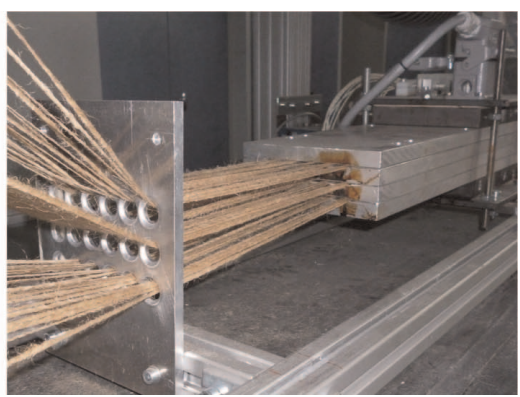

Figure 5. Bobbin creel for natural yarns and pre-drying of the fibres/yarns 
Construction Materials

Volume 166 Issue CM6
Natural-fibre-reinforced plastics

in actively bent structures

Gengnagel, Lafuente Hernández

and Bäumer
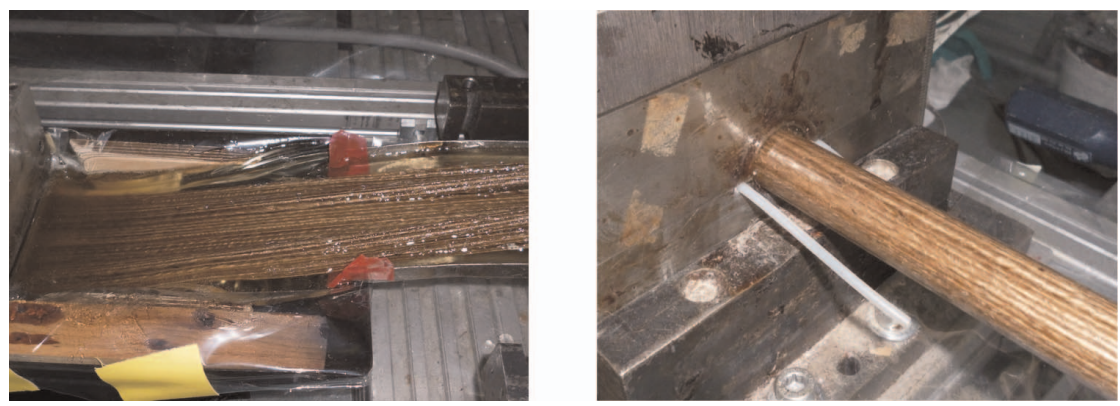

Figure 6. Impregnation of fibres in an open resin bath and pulling of the fixed profile from the die alternative to GFRP and as an upgrade from classic structural timber, NFRPs have a rather good ratio between bending elasticity and load-bearing capacity. However, the stress reserves of NFRPs after the bending process will be lower than with CFRPs or GFRPs owing to their lower ultimate strength. Further studies should focus on analysis of NFRPs' long-term behaviour and the temperature dependence of their mechanical properties.

\subsection{NFRP as material of choice for elastic gridshells}

Residual stresses resulting from the erection process of elastic gridshells are determined by the material and section properties of the profiles as well as the target geometry of the structure. In order to minimise these residual stresses, materials with a low modulus of elasticity and profiles with shallow sections are selected, such as at the timber Multihalle Mannheim (Germany, built in 1975) and the Weald and Downland museum (UK, built in 2002) gridshells.

Compared to conventional materials like timber or bamboo, emerging fibre-reinforced composites, with a lower ratio of

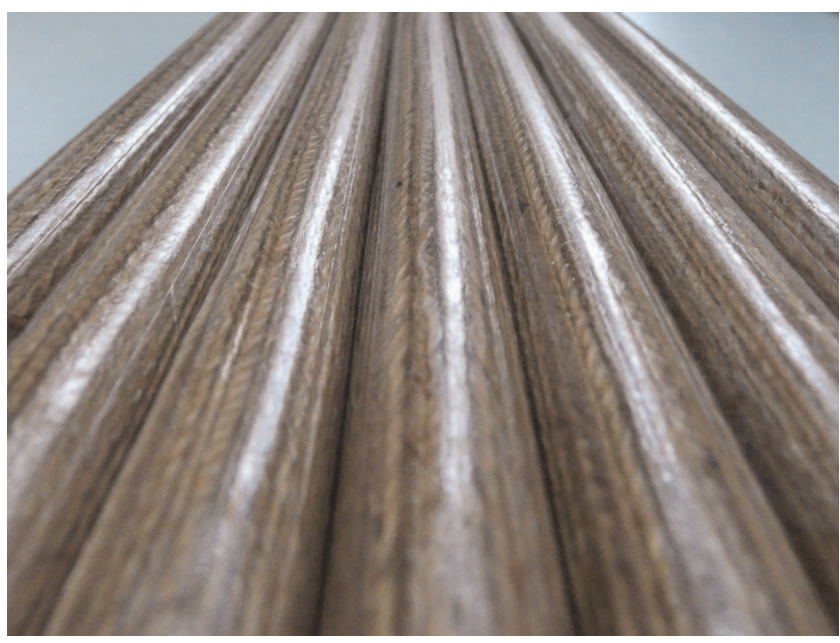

Figure 7. Pultruded NFRP circular tubes $20 \times 2 \mathrm{~mm}$ elastic modulus to bending strength, can be bent further while keeping lower values of utilisation. Thereby gridshell geometries with larger curvature, and subsequently higher rigidity, can be generated maintaining higher stress reserves for external loading. With a higher modulus of elasticity, fibre-reinforced plastics also offer better performance in terms of local and global stability. Moreover, compared to timber, pultruded fibrereinforced profiles have fewer limitations with regard to the length and cross section, so that weak points due to connections for profile prolongations can be avoided and their cross sections optimised according to specific structural requirements.

As presented in previous chapters, NFRPs exhibit a ratio between bending elasticity and strength low enough to be able to be considered as an upgrade from classical structural timber and an environmentally friendly alternative to GFRP. Nevertheless, the strong twisting of the natural fibre yarns (Figure 8) and their subsequent local concentration on circles made difficult an optimal wetting of the individual fibres and also generated resinous zones with lower fibre volume content in the finished sections, causing inhomogeneities in the material properties. Furthermore, owing to the evaporation during the pultrusion process of the humidity absorbed by the natural fibres from the surrounding air, flaws in the matrix in the longitudinal direction appeared on the pultruded tubes, reducing their bending and torsional strengths.

Before determining the measures to be taken to optimise the mechanical properties of the profiles, it is important to identify the type of structure that NFRP profiles are suitable for, followed by the magnitude and nature of the forces acting on that structure.

\subsection{Prototyping of a hemispherical elastic gridshell with an irregular mesh}

Elastic gridshells and FRPs have been identified as a highly appropriate merger of technologies, in which needs and capabilities complement one another extremely well. Therefore, a 1:1 prototype of an elastic gridshell with an irregular mesh was built 
Construction Materials

Volume 166 Issue CM6
Natural-fibre-reinforced plastics

in actively bent structures

Gengnagel, Lafuente Hernández

and Bäumer

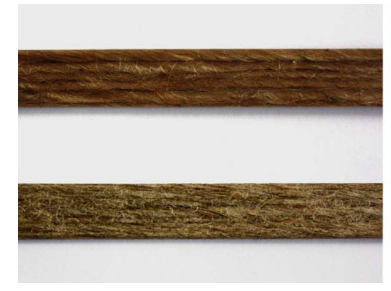

(a)

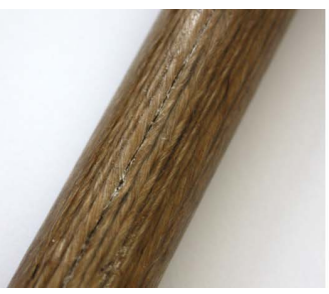

(b)

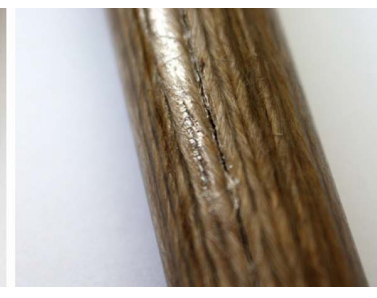

(c)

Figure 8. The strong twisting of the natural fibre yarns can be observed on (a) at top, the flat specimens, and bottom, a higher material homogeneity can be obtained with raw yarns. (b), (c) Flaws in the longitudinal direction appeared on the pultruded tubes

(see Figure 9). The final deformed geometry of the gridshell was recorded and compared with finite-element simulations for benchmarking and calibration.

The investigated gridshell consists of a hemisphere $10 \mathrm{~m}$ in dia. and mesh size varying from 0.66 to $1.27 \mathrm{~m}$. The topology of the grid was optimised by means of a non-linear variational algorithm in order to reduce the curvature of the profiles. The pultruded NFRP tubes, $20 \mathrm{~mm}$ in dia. with $2 \mathrm{~mm}$ thick walls, would have been structurally adequate for the gridshell if they had offered similar mechanical properties to the flat specimens. Nevertheless, owing to the longitudinal flaws in the tubes from pultrusion and their subsequently reduced bending and torsional strength, the mechanical properties were simply not consistent or reliable enough for application in the gridshell prototype. For this reason GFRP tubes were selected instead of NRFP for the gridshell prototype and subsequently the environmental benefits of using NFRP over GFRP were unfortunately not exploited. A similar section $20 \mathrm{~mm}$ in dia. and $3 \mathrm{~mm}$ thick was chosen for the $6 \mathrm{~m}$ long GFRP tubes ( $E$ modulus, $25 \mathrm{GPa}$ ). The bracing of the grid was introduced by triangulating the mesh with a third layer of profiles. The edge beam consisted of a ring made of oriented strand board (OSB) carrying the reaction forces of the elastically bent structure. Single pipe clamps were used for the connection of the tubes to the edge ring, double and triple pipe clamps for the interlayer connections and aluminium tubular connectors for the longitudinal joints.

In the non-linear FEA, the tubes and ring were modelled as beam elements and the interlayer connections as coupling elements. The corresponding material and sectional properties have been considered. Gridshells with irregular mesh size are usually built by bending the profiles independently from each other in an incremental process, which is generally more timeconsuming than by regular gridshells where the profiles are shaped as a whole grid. In order to optimise the erection process of the hemisphere, it was planned to bend it as an entire grid, as for regular gridshells.

As the mesh size of the grid is not constant, the profiles cannot start on a straight position and its distortion during the process of bending is constrained so that stresses on the grid are

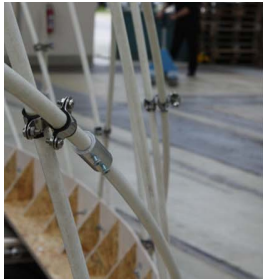

(a)

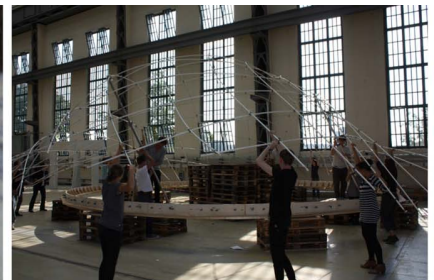

(b)

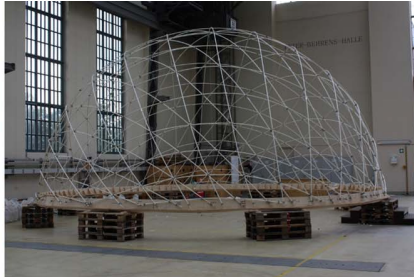

(c)

Figure 9. (a) Double pipe clamps and aluminium tubular joints were used for the interlayer and prolonging connections, respectively. (b), (c) The hemispheric gridshell with irregular mesh size was erected as a whole grid and braced with a third layer of profiles 


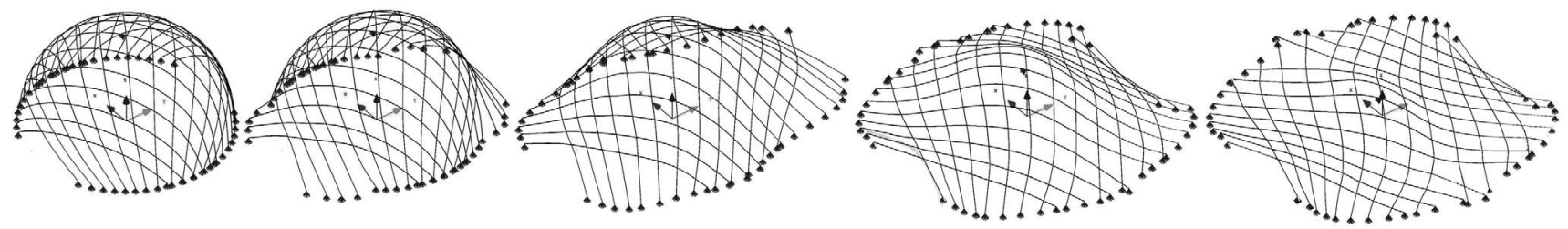

Figure 10. Numerical simulation of the starting grid shape

generated from its initial state and increase during the erection process. The objective of the numerical simulation was to ensure that these stresses did not exceed permissible limits. To estimate the starting shape of the grid with the FE model, the profiles were first independently bent using temporary virtual shaping cables, then connected to each other and finally released to obtain the equilibrium position (see Figure 10).

The maximum equivalent von Mises stress on the final structure represents a utilisation of $51 \%(73 \mathrm{MPa})$. Bending stresses $\sigma_{\mathrm{y}}$ accounted for $98 \%$ of the von Mises stresses at this point. In the physical prototype it is likely that torsion accounts for at least a small proportion of the total stresses because the connectors were not completely unrestrained in $x x$ owing to friction, whereas the FE model simulated perfect torsional freedom at the connections. The distribution of bending stresses in the $y$ - and $z$ axes is generally even, meaning that a rotationally symmetric section is therefore optimal. Furthermore, shear stresses due to torsion and shear forces should be considered. Axial forces do not result in significant material stresses but they tend to generate local and global stability problems due to buckling when external loading is applied.

After bending and fixing the grid to the edge ring, a third layer of tubes was added as a bracing layer. The structure was loaded with hanging sandbags of 10 and $20 \mathrm{~kg}$ in order to analyse bearing capacity. With a three-dimensional laser scanner (Faro ${ }^{\circledR}$ Laser Scanner Focus ${ }^{3 \mathrm{D}}$ ) the coordinates of the loaded intersection points, which were pre-marked with black and white identification labels, could be registered during the loading tests (see Figures 11 and 12).

The tabular presentation in Figure 13 shows the differences of geometry and deformations under loading between the real and simulated structures. Symmetrical and asymmetrical loads were applied hanging weights of $20 \mathrm{~kg}$ on, respectively, 34 and 19 intersection points (Figure 13(a)). The grid geometries resulting from the experimental and simulated models have been compared, without the bracing layer $\left(\Delta_{\text {Unbraced geometry }}\right)$ and with $\left(\Delta_{\text {Braced geometry }}\right)$. The location of the registered points on the prototype and the corresponding nodes on the FE model had a maximum deviation of $0.121 \mathrm{~m}$ for the braced geometry and $0.151 \mathrm{~m}$ for the unbraced geometry. The maximum nodal displacements of the modelled structure under loading $(0.053 \mathrm{~m}$ and $0.066 \mathrm{~m})$, which were to be found at the top of the structure in both cases (Figures 13(b) and 13 (c)), account for $67 \%$ and $63 \%$ of the real deflections $(0 \cdot 080$ and $0 \cdot 105 \mathrm{~m})$.

The deformed gridshell under symmetric and asymmetric loading (exaggerated by a factor of 10) is illustrated in Figure 14. It can be seen that local buckling prevails due to
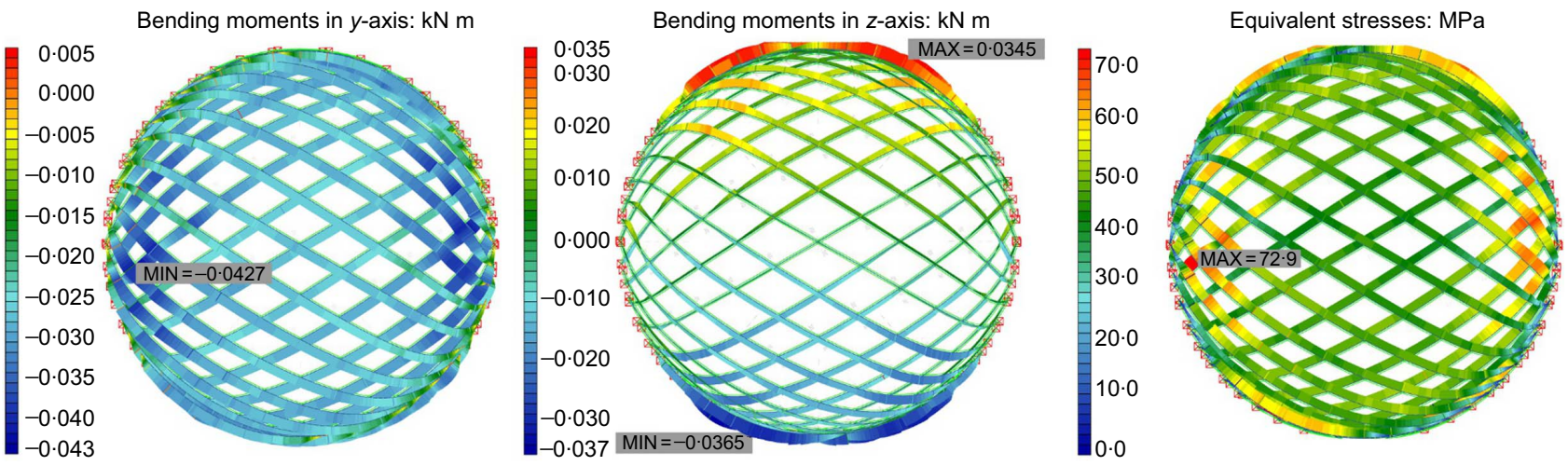

Figure 11. Resulting moments in $y$-axis and equivalent stresses on the grid after bracing 
Construction Materials

Volume 166 Issue CM6
Natural-fibre-reinforced plastics

in actively bent structures

Gengnagel, Lafuente Hernández

and Bäumer

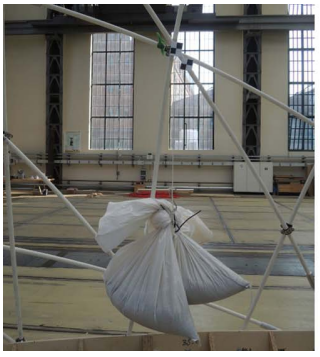

(a)

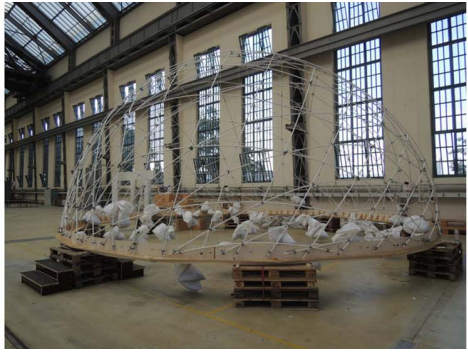

(b)

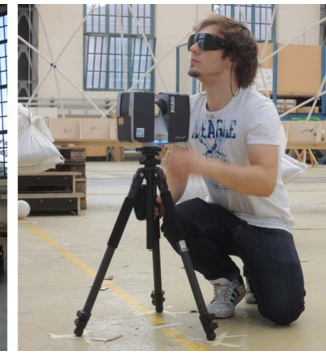

(c)

Figure 12. (a), (b) Loading tests on the hemispheric gridshell with sandbags. (c) Registration of the coordinates of the loaded nodes using a three-dimensional laser scanner

global stability problems. Profile segments from the third layer located on the top of the structure, with greater lengths, are more susceptible to buckling.

The differences between the real and modelled structures are mainly generated by inaccuracies in the simulation of the connection properties. During the erection and loading of the prototype, sliding on the interlayer connections occurred, as the contact forces on the clamp joints were not high enough, causing higher deformations. Further FE models with more precise connection elements, such as using spring elements, are planned.

Furthermore, imperfections induced by building the structure (e.g. by sawing the tubes or marking the interlayer and support connection points) or by registering the gridshell deformations under loading (e.g. locating the reference points or weighing the sandbags) are also the reasons for these differences.

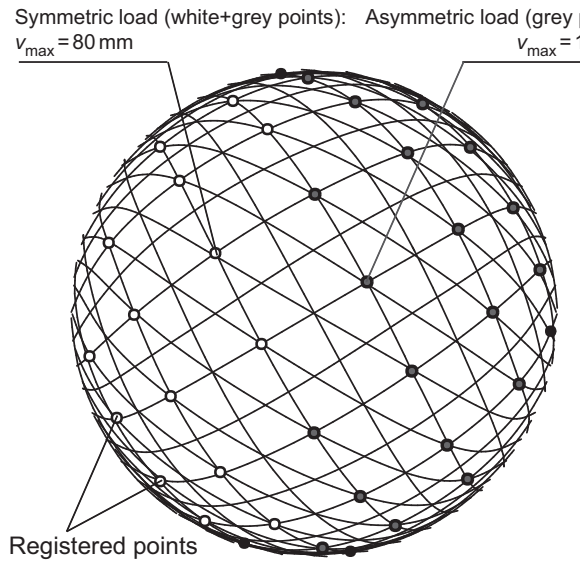

\begin{tabular}{c|cc} 
& $\Delta_{\text {braced geometry }}$ & $\Delta_{\text {unbraced geometry }}$ \\
\hline $\begin{array}{c}\text { Prototype } \\
\text { FEM }\end{array}$ & $0.121 \mathrm{~m}$ & $0.151 \mathrm{~m}$
\end{tabular}

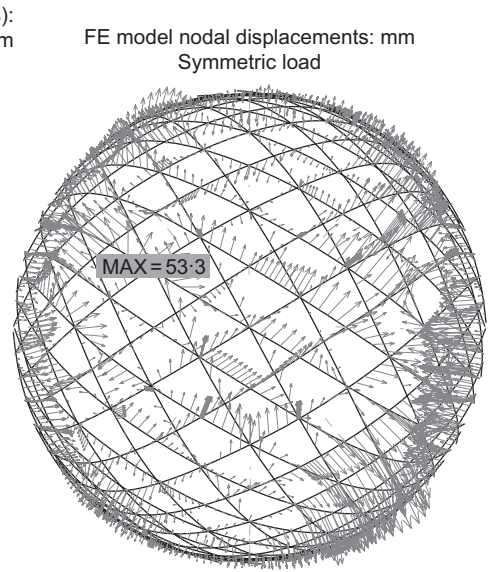

(b)

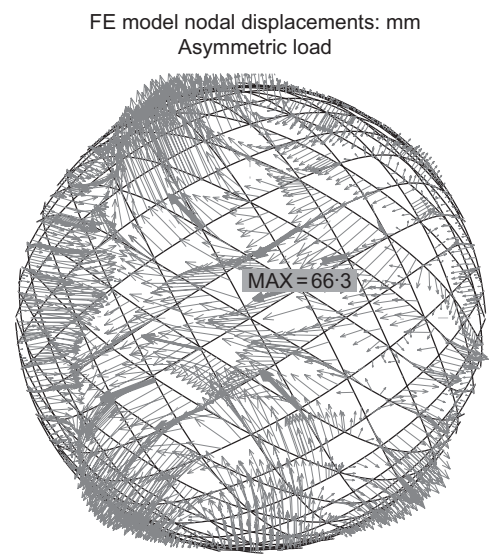

(c)

Figure 13. Comparison of the resulting geometry with and without bracing layer (unloaded structure) and of the maximum deformations under symmetric and asymmetric loading between real and simulated structures 
Construction Materials

Volume 166 Issue CM6
Natural-fibre-reinforced plastics

in actively bent structures

Gengnagel, Lafuente Hernández

and Bäumer
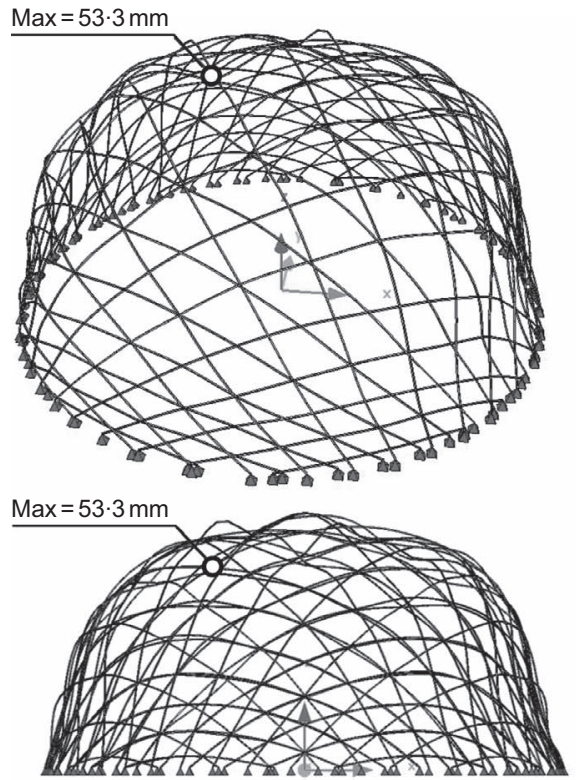

(a)
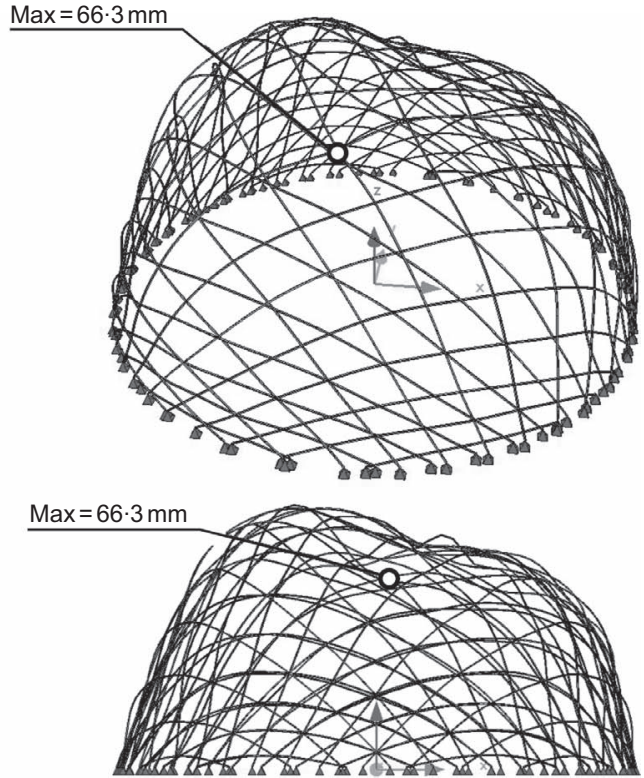

(b)

Figure 14. Deformation of the gridshell under (a) symmetric and (b) asymmetric loading

\section{Conclusion}

Although the flat test specimens made of natural fibres and organically based resin exhibited a ratio of bending stiffness to strength adequate for active-bending structures, the pultruded tubes presented significant flaws in the longitudinal direction due to a non-homogeneous distribution of the fibres in the matrix. Forces acting on the profiles of gridshell structures can be calculated by means of non-linear FE modelling. A hemispheric gridshell with irregular mesh size was selected in order to analyse the stresses to which the profiles are subjected. A 1:1 prototype was built to benchmark the numerical simulation, comparing the resulting geometries and loadbearing capacity. Profiles on grid structures are mainly subjected to bending moments. Certain shear strength also has to be provided because of shear stresses due to torsional moments and shear forces. In order to avoid resinous zones and consequent flaws on the pultruded NFRP tubes, increasing with it their bending and torsional strength, further experiments are planned, where the combination of yarns and raw yarns of natural fibres and the addition of an external reinforcement weave by the pultrusion of the profiles should be tested.

\section{REFERENCES}

Alpermann H and Gengnagel C (2009) Membranversteifte Bogentragwerke. Stahlbau 78(8): 531-536.

Alpermann H, Lafuente-Hernández E and Gengnagel C (2012) Case studies of arched structures using actively bent elements. In Proceedings of the IASS-APCS Symposium 2012, Seoul, Korea. Book of Abstracts, Paper No. FF-623, Full-paper in CD-ROM.

Angelov I, Wiedmer S, Evstatiev M, Friedrich K and Mennig G (2007) Pultrusion of a flax/polypropylene yarn. Composites Part A: Applied Science and Manufacturing 38(5): 1431-1438.

Bank LC (2006) Composites of Construction: Structural Design with FRP Materials. Wiley, Hoboken, NJ, USA.

Bäumer R, Lafuente-Hernández E and Gengnagel C (2013) Entwicklung von Querschnittsprofilen für Tragelement aus Naturfasern und biobasierten Harzen. BioForCE Final Report, Project No 22010211, Funding institution: Fachagentur Nachwachsende Rohstoffe (FNR).

Bouhaya L, Bavarel O and Caron JF (2011) Optimisation structurelle des gridshells. Proceedings of the 10th Colloque National en Calcul des Structures 2011 (CSMA), Presqu'il de Giens, France.

BSI (1999) EN 1999-1-1:2007: EN 1999-1-1:2007 Eurocode 9: Design of aluminium structures - Part 1-1: General structural rules. BSI, London, UK.

BSI (2004) EN 1995-1-1:2004: Eurocode 5: Design of timber structures - Part 1-1: General - Common rules and rules for buildings. BSI, London, UK.

Burgueño R, Quagliata MJ, Mohanty AK, Mehta G, Drzal LT and Misra M (2004) Load-bearing natural fiber composite cellular beams and panels. Composites Part A: Applied Science and Manufacturing 35(6): 645-656. 
Burkhardt B, Bächer M and Otto F (1978) Multihalle Mannheim: Dokumentation über die Planungs- und Ausführungsarbeiten a report on the sub-project 'Experience gained by buildings' Mitteilungen des SFB64, 38, Stuttgart, Germany (in German).

DIN (Deutsches Institut für Normung) (2007) EN 14125: 2007: Thermoplastic and flexible pipework for underground installation. DIN, Berlin, Germany.

Douthe C, Baverel O and Caron JF (2006) Form-finding of a grid shell in composites materials. Journal of the International Association for Shell and Spatial Structures, 2006, 47: 53-62.

Douthe C, Caron JF and Baverel O (2010) Gridshell structures in glass fibre reinforced polymers. Construction and Building Materials 24(9): 1580-1589.

Dweib MA, Hu B, O'Donnell A, Shenton HW and Wool RP (2004) All natural composite sandwich beams for structural applications. Composite Structures 63(2): 147-157.

Gengnagel C and Lafuente Hernández E (2011) Structural application of biocomposites in highly elastic structures. Proceedings of the the IABSE-IASS Symposium Taller, Longer, Lighter, London, UK.

Gensewich C and Riedel U (1999) Pultrusion von Konstruktionswerkstoffen aus nachwachsenden Rohstoffen. Die Angewandte Makromolekulare Chemie 272(1): 11-16.

ISO (International Organization for Standardization) (2008) EN ISO 291:2008: Plastics - Standard atmospheres for conditioning and testing. ISO, Geneva, Switzerland.

ISO (2009) EN ISO 527-5:2009: Plastics - Determination of tensile properties - Part 5: Test conditions for unidirectional fibre-reinforced plastic composites. ISO, Geneva, Switzerland.

ISO (2010) EN ISO 179-1:2010: Plastics - Determination of Charpy impact properties - Part 1: Non-instrumented impact test. ISO, Geneva, Switzerland.

Li X (2004) Physical, Chemical and Mechanical Properties of Bamboo and its Utilization Potential for Fiberboard

Manufacturing. Msc Thesis, School of Renewable Natural Resources, Louisiana State University and Agriculture and Mechanical College, Baton Rouge, LA, USA.

Lienhard J, Alpermann H, Gengnagel C and Knippers J (2012) Active bending, a review on structures where bending is used as a self formation process. Proceedings of the IASSAPCS Symposium 2012, Seoul, Korea. Paper FF-602, CDROM.

Mcquaid M (2006) Shigeru Ban. Phaidon Press, London, UK.

Peng Xi, Fan M, Hartley J and Al-Zubaidyc M (2012) Properties of natural fibre composites made by pultrusion process.

Journal of Composite Materials 46(2): 237-246.

Van de Velde K and Kiekens P (2001) Thermoplastic pultrusion of natural fibre reinforced composites. Composite Structures 54(2-3): 355-360.

Van de Velde K and Kiekens P (2002) Biopolymers: Overview of several properties and consequences on their applications. Polymer Testing 21(4): 433-442.

Zhu J, Chandrashekhara K, Flanigan V and Kapila S (2004) Manufacturing and mechanical properties of soy-based composites using pultrusion. Composites Part A: Applied Science and Manufacturing 35: 95-101.

\section{WHAT DO YOU THINK?}

To discuss this paper, please email up to 500 words to the editor at journals@ice.org.uk. Your contribution will be forwarded to the author(s) for a reply and, if considered appropriate by the editorial panel, will be published as discussion in a future issue of the journal.

Proceedings journals rely entirely on contributions sent in by civil engineering professionals, academics and students. Papers should be 2000-5000 words long (briefing papers should be 1000-2000 words long), with adequate illustrations and references. You can submit your paper online via www.icevirtuallibrary.com/content/journals, where you will also find detailed author guidelines. 